\title{
Colectivos artísticos en Bogotá. La transformación del quehacer artístico entre 1950 y 1970 promovida por El Búho y La Casa de la Cultura*
}

\author{
ARTIST COLLECTIVES IN BOGOTÁ. THE TRANSFORMATION OFART \\ PRACTICES BETWEEN 1950 AND 1970 PROMOTED BY EL BUHO AND \\ LA CASA DE LA CULTURA
}

ARTE COLETIVA EM BOGOTÁ. A TRANSFORMAÇÃO DO

EMPREENDIMENTO ARTÍSTICO ENTRE 1950 E 1970 POR EL BUHO E

LA CASA DE LA CULTURA

\section{Janneth Aldana Cedeño**}

Cuadernos de Música, Artes Visuales y Artes Escénicas

/ Volumen 9 - Número 2 / julio - diciembre de 2014

I ISSN 1794-6670/ Bogotá, D.C., Colombia / pp. 193-214

Fecha de recepción: 22 de agosto de 2014 | Fecha de aceptación: 25 de agosto de 2014. Encuentre este artículo en http://cuadernosmusicayartes.javeriana.edu.co/

doi:10.11144/Javeriana.mavae9-2.cabt

* El presente artículo presenta los resultados de la investigación "El desarrollo experimental del grupo de Teatro El Buho y la Casa de la Cultura de Bogotá. Transformaciones culturales en la sociedad colombiana a mediados del siglo XX", financiado por la Pontificia Universidad Javeriana.

* Docente de sociología de la Pontificia Universidad Javeriana. Adscrita al grupo de investigación Cultura, conocimiento y sociedad. 


\section{Resumen}

El artículo presenta las conclusiones de una investigación en torno a los procesos de modernización en el arte colombiano a mediados del siglo $X X$, en especial el teatro. Parte de la comprensión de este proceso se da a través de los intentos de varios artistas por lograr un espacio de creación conjunta que, al unir esfuerzos, permitiera cualificar no solo el desarrollo de diversas esferas artísticas sino el criterio del potencial público al cual sus trabajos iban dirigidos. El análisis se sitúa estrictamente en el periodo señalado, con el propósito de considerar las percepciones de los propios protagonistas, no la decantación posterior realizada por ellos o por investigadores provenientes de diversas disciplinas. Sin embargo, el resultado obtenido por estos colectivos no siempre fue el esperado en el corto plazo, debido, en buena medida, a condiciones ajenas al ámbito artístico.

Palabras clave: colectivos artísticos; teatro; cambio cultural; El Búho; Casa de la Cultura

\section{Abstract}

This article presents the conclusions of a research about the modernization processes in Colombian art, especially theater, in the mid-twentieth century. Part of the understanding of this process occurs because the attempts doing by several artists in order to achieve a space for joint creation that, with connected efforts, allowed them to qualify not only the development of various artistic fields but also the critical perspective of the potential audience of their works. Analysis is situated strictly in the period designated with the purpose of considering the actors' perceptions, not subsequent scrutiny performed by themselves or by researchers from different disciplines. However, the results obtained by these groups not always were those expected, mainly for external conditions to the art world.

Keywords: artistic collectives; theater; cultural change; El Búho; Casa de la Cultura

\section{Resumo}

Este artigo é o resultado de uma pesquisa sobre os processos de modernização na arte Colombiana em meados do século $X X$, especialmente no teatro. Parte da compreensão desse processo é feita a través das tentativas de vários artistas para obter um espaço para a criação conjunta que, unindo esforços, permitiu qualificar não só o desenvolvimento de vários campos artísticos, mas o critério do público potencial para o qual suas obras foram direcionadas. A análise abrange estritamente o período designado a fim de considerar as percepções dos próprios atores no lugar da decantação realizada posteriormente por eles ou por pesquisadores em diferentes disciplinas. Porém, o resultado obtido por esses grupos nem sempre foi o esperado no curto prazo, devido em grande parte a condições alheias ao mundo da arte.

Palavras-chaves: coletivos artísticos; teatro; mudança cultural; El Búho; Casa de la Cultura 


\section{INTRODUCCIÓN}

Las transformaciones sociales por las que han atravesado los grupos humanos corresponden en su mayoría a procesos no planeados por ellos mismos, pues sus propias posibilidades de hacerlo encuentran la enorme limitación de la complejidad del ámbito social. Esto no impide, sin embargo, que hombres y mujeres en múltiples ocasiones intenten redireccionar sus acciones de acuerdo con objetivos de distintos tipos concretados en conjunto tanto desde sus trayectorias vitales como desde las oportunidades históricamente configuradas, permitiendo la formulación de problemas específicos para un periodo determinado (Elias, 1998).

Colombia, durante el siglo XX, el caso más preciso y tal vez el más analizado, se enmarca en la República Liberal (1930-1946), momento de entrada a la modernidad soportada en el fortalecimiento del Estado, el impulso a la industrialización y el aumento de la participación política de nuevos sectores, si bien se trató más de una apertura liberal en términos económicos y conservadora en el terreno político (Corredor, 1992, pp. 165-193). Se logró cierta democratización en particular por la emergente clase media, clase consumidora que pudo apropiarse de algunos bienes culturales, patrimonio usual de las élites, aunque, por tratarse de un fenómeno urbano concentrado en las tres ciudades principales del país -Bogotá, Medellín y Cali-, su desarrollo fue bastante desigual viéndose los sectores menos favorecidos escasamente vinculados (Henderson, 2006, pp. 329-368).

Uno de los ámbitos donde los esfuerzos se expresaron por medio de políticas puntuales fue el cultural. La elite oligárquica que hizo de este periodo una república "elitista y popular" (Pecaut, 1985, pp. 132-135) que buscó acercarse a la modernidad "occidental" con las obras reconocidas de la "cultura universal" como modelo a imitar para el mejoramiento intelectual del pueblo (Sierra Mejía, 2009, p. 25). Con este propósito se diseñaron varias estrategias en aras de alcanzar los patrones culturales conducentes a la consolidación de un arte nacional, estrategias proyectadas y puestas en práctica principalmente por personas del Ministerio de Educación Nacional, quienes se encargaron de construir la representación de la cultura popular desde su aspecto folclórico, es decir, desde un ángulo bastante conservador y tradicionalista. Entre las reformas se cuenta la reorganización del mismo Ministerio y su división de Extensión Cultural, la creación de la Biblioteca Aldeana o la fundación de la Radiodifusora Nacional de Colombia (Silva, 2005).

La radio fue fundamental no solo para el proyecto cultural recién mencionado sino para la divulgación general de las artes a nivel nacional. El caso del teatro es bastante representativo de cómo el esfuerzo por desenvolverse en un nuevo medio contribuyó a la difusión del repertorio clásico y contemporáneo desconocido en el país. Además, abrió un espacio de formación y de experimentación que luego daría paso al movimiento artístico presenciado en la década de los sesenta del pasado siglo, momento clave para el desarrollo del arte dramático en Colombia. La radio y, más adelante, la televisión, fueron la puerta de entrada que no requería boleto costoso para asistir a este tipo de obras.

Con el ascenso a la presidencia de Manuel Ospina Pérez en la retoma del poder político por parte del Partido Conservador, este proyecto planteado por el liberalismo se abandona (Silva, 2006, p. 27), sin encontrarse posteriormente otro similar propuesto por el mismo Estado. Casi una década después empezaron a perfilarse nuevos intentos de transformación cultural provenientes de la elite intelectual económicamente prestante y de varios artistas con cierta trayectoria y reconocimiento. Algunas de estas personas se organizaron en colectivos cuyo 
eje se consolidó a través de un lugar, un espacio donde aglutinar diversas tendencias, propendiendo por la cualificación en su quehacer y el juicio estético de los potenciales espectadores. La visión subyacente de esta posición no descansaba ya en el ideario popular de la República Liberal, y si, por el contrario, en principio fue leída como extranjerizante y esnob, luego se orientará a los sectores estudiantiles y obreros como parte de un proyecto de cambio social de más largo alcance. Dos ejemplos claros de esta transición, pertenecientes a un mismo proceso, son El Búho y la Casa de la Cultura de Bogotá.

\section{ANTECEDENTES INMEDIATOS}

El primer tercio del siglo XX, en materia teatral, no presentó importantes modificaciones frente al panorama general del siglo XIX en Colombia: pocas compañías nacionales y menos aún extranjeras pasaban por los insuficientes escenarios capitalinos en representaciones con escasa asistencia de público. En 1948, diez años después de su primera designación como director del Teatro Colón, Bernardo Romero Lozano presentaba un diagnóstico desalentador de la actividad cultural programada en esta sala hasta finales de la década de los cuarenta. Concebido como el primer teatro de la nación, desde su apertura se obvió su principal función alrededor del "desarrollo y estímulo" del arte nacional. En comparación con otros teatros de la región -el Colón de Buenos Aires, el Municipal de Santiago de Chile o el Solís de Montevideo-, el Colón de Bogotá recibió permanentemente compañías mediocres, debido no solo a las dificultades para arribar a la ciudad cuando estas ya habían pasado por otras capitales latinoamericanas, sino también a los exiguos recursos asignados al sector cultural.

Se presentaban compañías de ópera de "mala muerte", de opereta y zarzuela, prestidigitadores y transformistas. Desde 1904 hubo intentos por formar grupos anexos a la sala, fracasados en su mayoría, pues se privilegiaban las obras hechas por extranjeros, "ilustres desconocidos" en música, danza y teatro, salvo contadas excepciones ${ }^{1}$. El panorama se complicó desde finales de los años veinte, con la apertura de numerosas salas de cine en los barrios de la ciudad, propiciando que las actividades del Colón se ampliaran a bailes de sociedad y convenciones políticas, gremiales o académicas. Para Romero Lozano era claro que esta situación debería cambiar si se quería estimular un arte propio:

El Teatro de Colón, de propiedad del gobierno nacional, no debe seguir siendo ese lujoso inmueble oficial, apenas dedicado al pasajero y costoso albergue indiscriminado de espectáculos óptimos, regulares y hasta decididamente indignos de su escena. Elevado a la categoría de organismo cultural, creándole esas instituciones propias de que ha carecido, con un personal director idóneo e importado puesto que el país mal puede disponer de esos elementos técnicos, entonces sí, el Teatro de Colón cumplirá su misión imponderable e impostergable, de auténtico estimulador de la cultura patria. (1948b, p. 4)

Este balance sintonizaba con el pensamiento generalizado de los funcionarios encargados de la política cultural, siendo bastante ajustado a la situación del momento. A la escasez de salas y poca asistencia de público se sumaba la precaria formación de los artistas y demás involucrados en el acto de creación, circulación y difusión de la obra de arte, lo cual explica la insistencia por la conformación de grupos que, en la misma práctica, posibilitaran la adquisición y desarrollo del conocimiento necesario para avanzar en esta labor. Se reclamaba la ampliación de espacios donde se construyera un gusto y juicio estético en la conexión entre 
creación y recepción alrededor de varias corrientes, en especial las modernas, permitiendo entablar diálogos con lo que sucedía en el resto del mundo y, de esa manera, contribuir a la superación del aislamiento que había mantenido el país durante largo tiempo. Se hizo evidente la importancia de atraer público sin descontar la búsqueda de apoyos estatales, fundamentales para sostener económicamente actividades de interés cultural.

Romero Lozano cesó su labor en el Colón para asumir la dirección musical en la Radiodifusora Nacional. Ya se ha mencionado cómo, desde el Estado, se reorganizaron algunas instancias durante los primeros años de la República Liberal, sumadas a la creación de todo un programa de difusión cultural concentrado en los medios de comunicación masiva, el cinematógrafo y la radio, con el ánimo de llegar a una población que para la década de los cuarenta era en su mayoría analfabeta. La Radiodifusora se inauguró el 1 de febrero de 1940, siendo nombrado director Rafael Guizado quien, con Hernando Vega Escobar, también se encargó inicialmente de la conducción del grupo de radioteatro (además de la Compañía Nacional del Teatro Colón creada en 1943). Desde 1950, con la dirección de Romero Lozano, hasta 1960 aproximadamente, con Fausto Cabrera, primero con el grupo de Teatro del Distrito y luego con El Búho, se consolida el periodo denominado la "época de oro" del radioteatro en Colombia (Téllez, 1974, p. 72). Durante este periodo se difundieron las piezas más importantes del arte dramático a nivel mundial, clásico y contemporáneo -Sófocles, Shakespeare, García Lorca o Wilder-, al tiempo que se promovía la difusión de la producción nacional -Tomás Carrasquilla, Oswaldo Díaz Díaz o Guillermo Valencia- (Boletines de la Radiodifusora Nacional, 1958). Los domingos cientos de radioescuchas se encontraban en la noche para seguir los montajes cuando aún no hacía su aparición la radionovela, de nuevo bajo la intención de elevar el gusto y la capacidad intelectual del público por medio del arte ("Dos tendencias del teatro nacional", 1943, pp. 333-335).

Un sector fundamental para cumplir con estos propósitos fue el universitario. Para empezar, este era un público a cautivar por los mismos recursos que poseía: número creciente de personas con disposición crítica y con posibilidad de contribuir en la creación artística desde sus diferentes áreas de formación; estudiantes y docentes en un lugar que iba adaptándose a las nuevas circunstancias y que por tanto podía, en parte, aliviar la escasez de salas de teatro y demás lugares de exposición y divulgación. El arte en las universidades funcionó más allá del apoyo de las directivas académicas y se constituyó en otro factor que fue complejizando este campo pues allí surgieron grupos de tipo experimental -el primero de ellos se fundó en la Universidad Nacional de Colombia en 1945 bajo la dirección de Romero Lozano (Argaez y Franco, 1986, p. 23)-, los cuales, al estar alejados de las formas tradicionales, innovaron muchas veces sin buscarlo, acercándose así a las vanguardias del momento. Como consecuencia de las relaciones entre estos diversos agentes -elites intelectuales económicamente prestantes, grupos artísticos que sumaban cierta experiencia y el creciente sector estudiantil- se configuraron otras instancias de intercambio que impulsaron el despegue de proyectos con objetivos más precisos a propósito del camino a seguir para la renovación artística y cultural en el país.

Una de estas instancias que cobra importancia al reunir a todos los sectores ya mencionados y abrirle camino a otros fue el Festival de Teatro de Bogotá. En su primera versión se denominó internacional, no porque concursaran compañías extranjeras, sino porque parte importante del soporte económico y artístico provino de las embajadas y desde allí salieron los grupos que se decidieron por montar obras en su lengua natal. Se realizó entre octubre y noviembre de 1957 con la intención de crear una franja cultural en la que se mostraran las 
obras que duraban poco tiempo en cartelera por las pocas salas existentes en la ciudad; sin embargo, este objetivo rápidamente se orientó a movilizar el sector cultural en Colombia, razón por la cual en las siguientes versiones se intentó vincular a las regiones. El Colón fue de nuevo el escenario que sirvió para el encuentro de grupos profesionales -de radio, televisión y las escuelas de teatro como la Nacional de Arte Dramático y la del Distrito-, los provenientes de las universidades y aquellos fundados por aficionados, entre los que se encontraban los apoyados por las embajadas.

Si bien, otra vez, una de las principales dificultades fue la escasez de público mantenida a pesar de la amplia propaganda en los medios escritos, en estos mismos medios se manifestó una crítica emergente que se esforzaba por dar cuenta de todos los aspectos de la obra y su presentación; trataban de seguir los patrones europeos y norteamericanos, pues varias de las personas encargadas de esta labor tendían a comparar con otros montajes observados por ellas mismas en el extranjero². A esto se sumó la masiva conformación de grupos artísticos, unos de corta existencia, reducida a los días del festival, otros con propósitos más ambiciosos que expresaron las preocupaciones alrededor de la realización de un evento artístico de tal magnitud: exiguo personal calificado en la mayoría de áreas a cubrir; insuficiencia de los recursos económicos procedentes del sector público y privado y, de nuevo, un público incapaz de sostener, material y críticamente, cualquier iniciativa artística, más aun cuando, frente a las obras de vanguardia de carácter experimental, se revelaba cierta incomprensión resultante en aburrimiento (Norden, 1957-1958).

Para la segunda versión, los organizadores del festival quitaron el adjetivo internacional, trataron de ser más estrictos en la selección de los trabajos y de vincular colectivos regionales con el interés de extender su influencia. Por otra parte, algunos grupos con trayectoria reflexionaron sobre su quehacer -contrariamente al panorama prometedor del ideólogo del festival, el húngaro Ferenc Vajta, sobre lo que había movilizado el festival en cuanto al desenvolvimiento de un arte nacional (Vajta, 1958)-, ocasionando que para la tercera versión se dudara de la calidad estética del evento pero, fundamentalmente, de su función social.

Entonces, si en principio se manifestó una visión esperanzadora sobre las posibilidades de desarrollo de un teatro moderno nacional, luego apareció una crítica relacionada especialmente con los mecanismos para lograrlo. La primera versión del festival se leyó como la manera idónea para dar un mayor y mejor apoyo a las personas dedicadas al teatro, mientras se trabajaba por atraer a un público más numeroso, pues el nivel teatral en el país era bastante mediocre (Moscovici, 1957). Solo así podría surgir un teatro moderno -de la vanguardia del momento-, bueno -con los requerimientos básicos artísticos y técnicos-y nacional -al montar las innumerables obras de dramaturgos colombianos que no habían podido llevarse a escena por la escasez de grupos. Se aplaudió que el teatro fuera la mejor expresión "cultural del clima de libertad y estabilidad política" que recuperaba el país con la caída del gobierno militar de Gustavo Rojas Pinilla y la formación del Frente Nacional (Gómez Valderrama, 1958, p. 13).

Fausto Cabrera atribuyó estos cambios a la emergencia de los grupos experimentales, ya que estos, y no las compañías tradicionales, habían logrado superar la caduca tendencia española y la propensión nacional al folclorismo y el costumbrismo. Eventos como el festival servían para mantener una actividad e intercambio constante entre actores, directores, autores y técnicos en la confrontación con el público (Cabrera, 1958b, p. 17), mientras para Buenaventura eran la oportunidad de superar el centralismo, expresión del atraso en las provincias producto de una burguesía inexistente y de una clase media desinteresada que era necesario 
conquistar junto con el público popular (1958a, p. 22). Estas posturas, propias de finales de la década de los cincuenta, comparten en su mayoría la certeza de la cualificación del arte por medio de la escenificación adecuada de las obras reconocidas de la vanguardia mundial; solo así sería posible cumplir con la función social planteada en términos de la formación de un público crítico capaz de sostener buena parte de la práctica artística. Es la razón por la cual los grupos experimentales fueron centrales, al esperarse de ellos que despertaran al país de la parálisis impuesta por la inexistencia de una tradición teatral y por los clichés copiados de las compañías extranjeras visitantes (Pontón, 1958a, p. 18).

Pero no pasaron más de tres años antes de manifestarse las esperanzas rotas sobre las probabilidades reales de progreso del arte nacional. Era imposible cumplir con la tarea de la formación del público cuando se había "comenzado por el final": trayendo un teatro de "avanzada" difícil de digerir por un espectador "naturalmente retrasado". ¿Cómo hacer un teatro, por ejemplo existencialista, cuando la población colombiana en su mayoría no sentía estas "angustias metafísicas" que no correspondían a su desarrollo como sociedad? (Rizzo Otero, 1959). Un festival lograría sus objetivos solo cuando se fortalecieran las escuelas de teatro para hacer de estos eventos una "necesidad de la sociedad en su conjunto" (Drezner, 1959), con artistas que solo viendo de primera mano del teatro mundial pudieran comprender cómo podría ser uno de calidad (Vivas, 1959).

Sin embargo, no se puede negar que, gracias a este tipo de espacios de circulación y difusión, los propios artistas empezaron a pensar sobre su práctica y sobre las posibilidades de reorientarla. Tal fue el caso de un grupo como El Búho, que, para el cuarto festival, decidió no participar, alegando problemas con la organización por no tener en cuenta el criterio de los artistas, confundiendo al público con la mezcla entre profesionales y aficionados. Añadían que no había justificación para no abrir los límites y conocer, mínimamente, lo que acontecía en la región (El Espectador, 11 de septiembre de 1960) con el trabajo de varios colectivos cuyas producciones se habían caracterizado ya como nuevo teatro.

\section{EL BÚHO. PRIMER COLECTIVO INDEPENDIENTE EN EL PAÍS}

Estas experiencias permitieron decantar años de trabajo y sopesar las acciones que llevaron a los éxitos o fracasos de distintos proyectos tendientes a la cualificación de artistas y público. El diagnóstico concluyó que buen número de los reveses se relacionaba con la dificultad, por causas exógenas, de realizar una labor permanente y continua a través de los grupos. Estos habían funcionado mucho mejor que las escuelas, pues allí se formaban las personas en la misma práctica artística -y no en clases de salón- al tener que resolver problemas concretos, en primera instancia relacionados con la creación, pero que, inevitablemente, derivaban en la comunicación con los posibles espectadores. Así, en cuanto a teatro se refiere, muchas de las agrupaciones, en especial las universitarias, al tiempo que conformaron sus equipos programaban charlas y debates, como sucedió con el Teatro Club de la Universidad de América, el cual, a partir de 1957, con base en su grupo experimental y a través de mesas redondas, se planteó discutir sobre el arte dramático y sus oportunidades de desarrollo en una sociedad como la colombiana. El trabajo con grupos consolidados no se podía pensar entonces sin la conformación de un público que retroalimentara y diera sentido a su labor.

La referencia al público ausente y al asistente sin formación no es exclusiva de este periodo y tampoco de este contexto. Varios investigadores han notado que parte fundamental 
del proceso de autonomización (siempre relativa) del ámbito artístico está conectado con la constitución de un mercado anónimo de agentes con disposición y capacidad para pagar por los bienes artísticos. Por ejemplo, Pierre Bourdieu establece para la emergencia del campo literario francés la ruptura operada gracias al ascenso de la burguesía y la apertura que esta ocasiona de un nuevo mercado de comercialización de obras de arte, en donde el encuentro entre una clase específica de público y un tipo particular de bienes conduce a la legitimación artística. El rompimiento posterior con la burguesía hace que el campo empiece a determinar las reglas propiamente artísticas por medio del mercado de producción restringida y no a través del mercado de gran producción (Bourdieu, 2003), es decir, gracias a otros artistas e intelectuales y no al público masivo, dicotomía que caracteriza al arte moderno (Bourdieu, 1995, p. 176).

La configuración de un campo artístico relativamente autónomo se relaciona con cambios externos como el aumento de la población escolarizada, que incrementa a la vez sus recursos para consumir bienes artísticos o el crecimiento del número de artistas con capacidad de sobrevivir gracias a su profesión y no a través de otras actividades. Pero el aspecto fundamental es la ampliación del mercado de consumidores y su expansión; algo similar sucede con el universo de posibilidades de los artistas alrededor de la innovación de su quehacer. A la misma conclusión llega Howard Becker, a propósito de la constitución de los "mundos del arte" (1982), sostenida en actividades cooperativas entre distintos agentes involucrados con la producción, circulación y consumo de las obras de arte, quienes crean y mantienen el prestigio artístico así como las apreciaciones alrededor suyo. De nuevo, el mercado artístico es fundamental al condicionar los estilos, las tendencias y las formas generales de producción ya que dichas redes le permiten una constante adaptación a las transformaciones sociales (Altamirano, 2002, pp. 3-4).

A propósito de la preocupación por la cualificación del arte en el país y del público que la sostuviera, aparece una serie de colectivos con propósitos puntuales en este ámbito, entre ellos El Búho. Su origen inmediato se halla en la Escuela del Distrito, institución fundada tres años después de la creación de la Escuela Nacional de Arte Dramático (1951), primera en su género en el país, la cual fue pensada bajo la necesidad de formación del personal idóneo para desempeñarse en el Colón y en el espacio ganado en la radio (Teatro Colón. Escuela de Arte Dramático, 1951-1952). El Departamento de Extensión Cultural del Distrito de Bogotá apoyó la creación de la Escuela de Teatro del Distrito y el grupo -en ocasiones aparece con el nombre de Teatro Experimental-gracias a que, desde sus inicios, el proceso pedagógico estuvo ligado a la participación en montajes y su exhibición ante los espectadores.

Fausto Cabrera, director español exiliado, con larga trayectoria en el terreno, se encargó tempranamente de la escuela, que de manera clara inició con una intención experimental tratando de seguir, en parte, el camino transitado por algunos grupos universitarios de Chile y Argentina que, a través de la ruta experimental, contribuyeron a la renovación del teatro en sus respectivos países (Font Castro, 1955). A esta labor de formación e indagación se añadía la configuración de un público por medio de un "teatro móvil" (El Espectador, 16 de agosto de 1958), iniciativa conjunta con la Secretaría de Educación para llevar el teatro de "fácil comprensión" a los barrios y así no reducir las presentaciones a las insuficientes salas de la ciudad. Durante este periodo, Cabrera fue además mano derecha del director japonés Seki Sano en el Instituto de las Artes creado para él durante el gobierno de Gustavo Rojas Pinilla. 
La presencia de Seki Sano se reconoce como el suceso detonante en la creación de El Búho. Como parte del programa de difusión masiva propuesto durante el gobierno de Rojas Pinilla, quien a un año de estar en la presidencia, en 1954, inauguró la Televisora Nacional, la formación del personal necesario para desempeñarse en este medio se convirtió en una de las prioridades del gobierno. Para entrenar a los futuros actores se invitó al maestro japonés a finales de 1955, quien propuso la creación de una escuela con materias prácticas y teóricas desde la cual uno de sus aportes destacados fue la difusión del método de Constantin Stanislavski (El Espectador, 19 de septiembre de 1955). El tiempo que estuvo en el país fue corto, al ser expulsado (era un japonés relacionado con el Partido Comunista enseñando el método de un director que alcanzó a pertenecer a la Unión Soviética), pero con la labor posterior de sus alumnos (Cabrera, 1958b) se inició parte importante de la renovación en la escena teatral dada en el tránsito de los años cincuenta a los sesenta.

Cabrera fue a su vez expulsado de la Escuela del Distrito. En su retiro lo acompañaron varias personas con quienes venía trabajando y quienes se convirtieron en los miembros del Nuevo Teatro Experimental, el cual ya aparece en los festivales de teatro y en algunos radioteatros, luego llamado El Búho. Según Aristides Meneguetti, uruguayo en buena parte dedicado a la crítica artística en el mismo lapso en que Marta Traba ocupaba los principales espacios periodísticos en este ámbito, El Búho fue una propuesta suya, pues él mismo, Meneguetti, ya había conocido una experiencia similar en Ecuador, sustentada en una cooperativa de actores con el mismo nombre. Allí, artistas provenientes de distintas corrientes habían sumado esfuerzos para crear un espacio independiente que permitiera avanzar en el desarrollo de una tendencia moderna. Cabrera, Santiago García y Mónica Silva estuvieron a la cabeza del proyecto en la búsqueda de un lugar y de los primeros recursos para empezar a funcionar.

La adecuación de la sala se hizo en pleno centro de la ciudad. Meneguetti expresó en su momento que la intención era conseguir un espacio para favorecer el encuentro de "intelectuales, artistas, directores y dramaturgos" nacionales y extranjeros con la posibilidad de formular sus ideas libremente (Meneguetti, 1959):

(...) como artistas de este continente, una de nuestras preocupaciones más imperiosas es la de ir creando un teatro nacional con expresión propia y con sentido americanista, sin caer en lo folclórico y lo anecdótico. Creemos que el primer paso para este logro es, antes que nada, un movimiento teatral de importancia; la formación de un verdadero profesionalismo que cree los elementos necesarios del teatro, y la conciencia clara y precisa que se necesita en cualquier actividad de tipo artístico. (Arcila, 1983, p. 46)

Alrededor del teatro se reunieron una serie de artistas, muchos de los cuales habían colaborado con los montajes, especialmente en el aspecto escenográfico, y ya tenían cierto renombre, como Enrique Grau, David Manzur, Eduardo Ramírez Villamizar, Omar Rayo o Fernando Botero, y músicos como Luis Antonio Escobar y varios intelectuales que propusieron debates y conferencias sobre temas artísticos del momento. Con base en un "Club de amigos", no solo conocedores del arte sino personas con recursos económicos ${ }^{3}$, se sostuvo esta iniciativa durante algunos -más bien pocos- años. A todos los unía un interés por el trabajo experimental y por lograr acercarse a las tendencias mundiales de vanguardia.

El colectivo se convirtió en uno de los núcleos intelectuales de la ciudad, siendo el teatro el ámbito en que tuvieron mayor éxito. Un tren pulman llamado Hiawatha de Thorton Wilder, montada primero en 1958 como Nuevo Teatro Experimental y repuesta un año después como 
El Búho, en su primera versión, fue considerada la mejor obra del festival al tener buena acogida entre críticos y público; un "excelente resultado" para un "elenco de aficionados". Esta obra podría ayudar a acabar con los prejuicios en contra de la construcción de un teatro nacional, pues fue una "verdadera revelación" ("Atmósfera teatral en el Colón", 23 de agosto de 1958) -aunque desde algunos sectores se manifestó un desacuerdo por haberle otorgado el premio a mejor dirección, apareciendo críticas sobre la precariedad en este terreno así como en el trabajo actoral ("Ecos del II festival: comentarios al fallo del jurado", 23 de septiembre de 1958).

La primera sala del colectivo se inauguró el 21 de noviembre de 1958 con La causa encarnada de Adamov y El club de los mentirosos de Ghelderode. Era

(...) un teatro pequeño, en la Avenida Jiménez $N^{\circ} 10-34$, de Bogotá. El escenario parecía una habitación de mínimo tamaño, y su cupo era solamente de cincuenta personas, cuyas rodillas chocaban unas contra otras, dada la estrechez del espacio (...) El público sentía estar dentro del escenario, y hasta la más pequeña de las miradas era percibida por todos (...) Los actores entraban y salían por entre el público, por un camino que en los días de estreno era imposible (...) En la parte de arriba del teatrico, en la entrada, había un pequeño bar donde el público y nosotros (los actores) tomábamos tinto y aguardiente. (Reyes, 1960, p. VII)

Inicialmente, se propuso montar una obra cada semana -aunque resultaron ser dos por mes-, pues el colectivo contaba con varios directores, cada uno con la posibilidad de tener equipo independiente -algo que tampoco se dio-, todo siguiendo el propósito de mantener un repertorio. Si bien la cabeza principal era Cabrera, pronto se destacaron otros directores como García, Marcos Tychbrojcher, Sergio Bischler, Dina Moscovici y Carlos José Reyes. Tal fue la acogida que en poco tiempo tuvieron que trasladarse a un espacio más grande, el Teatro Odeón, ubicado en la Av. Jiménez con Cra. 5, inaugurando esta sala con Asesinato en la Catedral de Tomas Elliot, bajo la dirección de Cabrera y Reyes:

Pero un día nos aburrimos. Las dos obras que se presentaban cada mes, iguales en duración, con la misma cantidad de actores e interpretada siempre por los mismos, comenzó a limitar las posibilidades de hacer teatro de verdad, dado que no podían presentarse obras "grandes" del repertorio universal, así como tampoco podían hacerse grandes escenografías y no podíamos tampoco pensar en grandes proyectos. El hecho de que día a día nos fuésemos volviendo profesionales del teatro, así como que el teatro nos fuese absorbiendo nuestro quehacer cotidiano, nos hizo pensar en el hecho apenas lógico de que lo que habíamos de hacer era trasladarnos a un recinto tal que nos permitiese realizar los proyectos ambiciosos que día a día íbamos soñando. (Reyes, 1960, p. VII)

Durante tres años -de 1958 a 1961- lograron mantenerse bajo el proyecto inicial captando la atención de público y crítica. Entre las obras que montaron, algunas pertenecían a tendencias que apenas se estaban conociendo en el país, como La princesa Aoi de Yukio Mishima, primera obra de teatro Nöh puesta en escena por un grupo colombiano. Fue dirigida por Santiago García, quien además hizo la escenografía al estilo "muy japonés", desde el manejo de sombras hasta el vestuario, con el apoyo del pintor Gonzalo Ariza en la selección y uso de algunos implementos (Duque Mesa y Prada Prada, 2004, p. 114). Esta relación entre artistas plásticos y directores, como ya se ha mencionado, no es nueva, pues estuvieron cerca durante varias décadas alrededor de los montajes. Además del Teatro del Absurdo, que también lleva- 
ba un tiempo reciente de introducción al país ${ }^{4}$, y a pesar de la intención de El Búho de ponerse a tono con lo que sucedía en torno a la vanguardia mundial, otra de las tendencias presentes en unos cuantos directores fue la puesta en escena de obras de autores nacionales. Así lo hizo Cabrera al dirigir HK 111, del nadaísta Gonzalo Arango (febrero de 1959), Amor de chocolate, de Reyes (junio de 1960) -quien fue uno de los primeros promotores del teatro infantil-, o Los pasos del indio, de Manuel Zapata Olivella (abril de 1961).

Otro de los ámbitos en los que el grupo se desenvolvió fue la radio con los radioteatros de especial relevancia en la franja nocturna dominical, continuando con los programas ya iniciados por Romero Lozano. Para este medio se ha señalado cómo varias de las obras aparecen en principio con el nombre de Teatro Experimental del Distrito (entre marzo y agosto de 1958) -Opilión de Roberto Triana Arenas o La nieve estaba sucia de Georges Simenón-y más adelante como El Búho (de noviembre de 1958 a febrero de 1961) -Arlequinada de Terence Rattigan, La señora Dulska de Gabriela Zapolska, Melisa de Nikos Kazantzakis, El viaje maravilloso de Vladimir Maiakovski, Ardéle de Jean Anouil, El discípulo del diablo de Bernard Shaw, Larga cena de navidad de Thorton Wilder, Emperador y Galileo de Henrik Ibsen, entre muchas otras dirigidas en su mayoría por Cabrera-. Un buen número de montajes también pasó a trasmitirse a través del teleteatro, conformando equipos de trabajo que se desenvolvían en diversos escenarios, con lo cual se logró la formación de un personal competente para la programación cultural del momento.

Si bien la actividad central giró en torno al teatro, frente a las escasas posibilidades de encontrar espacios comunes de discusión y de intercambio, El Búho amplió su programación hacia otras esferas con el ánimo de abrir un espacio crítico, como lo fueron las conferencias y debates que tuvieron lugar en su sede. Allí se encontraban personas provenientes de diferentes disciplinas para discutir alrededor de montajes -como la charla orientada por un psiquiatra en torno a El dulce pájaro de la juventud de Tennesse Williams, dirigida por Julio Nieto Bernal (El Siglo, 29 de junio de 1960)- u otros temas artísticos -por ejemplo, Marta Traba se encontró con el artista plástico ecuatoriano Oswaldo Guayasamín para la tertulia "Dos puntos de vista sobre la pintura americana" (El Espectador, 29 de julio de 1960) o la recitación de poemas a cargo de la actriz argentina Nélida Quiroga, quien con su grupo hizo una breve antología de poesía hispanoamericana (El Siglo, 27 de abril de 1960).

Al tener entre sus principales objetivos ponerse al día con el teatro de vanguardia mundial, en varias ocasiones el grupo fue acusado de elitista y extranjerizante (Cabrera, 1979). Las críticas sobre el rumbo que tomaba el Festival de Teatro con las obras de "avanzada", viéndolas como obstáculos para el desarrollo de un teatro nacional digerible para la mayoría de la población colombiana o por lo menos para los capitalinos, son muestra de ello. Rizzo Otero, crítico de El Espectador, insistía en este punto, más cuando veía con beneplácito la labor de grupos como La Buhardilla (El Espectador, 25 de septiembre de 1960), creado en 1960 bajo la dirección de Alfonso Graíño, cuyos miembros manifestaban explícitamente su anhelo de hacer un arte que no se limitara a una elite intelectual sino que llegara a todos los sectores para el "adelanto cultural del país" (El Espectador, 18 de septiembre de 1960). Para este momento, es decir, los primeros años de la década del sesenta, buena parte de los detractores de El Búho acogían la caracterización de un teatro nacional representada por personas como Luis Enrique Osorio, descrito como un incansable explorador de lo "colombiano, contra extranjerismos y sin esnobismos" (Andrade González, 1966). Osorio consideraba que este nacionalismo teatral 
cuyo éxito se había manifestado desde comienzos de los años cuarenta consistía en que los autores tuvieran como temas su propio ambiente, se hiciera interpretar por autores nacionales y que el público fuera en masa a la sala del Municipal (Osorio, 1961).

Sin embargo, los miembros de El Búho intentaron acercarse a un nuevo público, para lo cual se trasladaban a centros culturales en los barrios de la ciudad y a otros lugares como fábricas y escuelas en la periferia. Fue quizás uno de los primeros colectivos experimentales en entender que para tener una creación propia deberían antes empaparse de lo que acontecía en el campo teatral, no solo en su labor como artistas sino en la relación que establecieran con los espectadores. Este conocimiento era necesario para poder juzgar y criticar, superando las tendencias tradicionales en el país apoyadas en un arte "retórico y ladrilludo", propio de la herencia española, o el caracterizado por la facilidad y chabacanería que se encontraba no pocas veces en el costumbrismo y el teatro popular (Duque Mesa y Prada Prada, 2004, p. 101).

En 1960, el grupo decidió no participar en el IV festival. Para ese momento, sus integrantes ya eran bastante reconocidos, así que pudieron hacer resonar sus opiniones negativas alrededor de un evento que mezclaba, sin ningún criterio, a grupos profesionales con aficionados (El Espectador, 11 de septiembre de 1960), impidiéndoles alcanzar así uno de sus propósitos alrededor de la formación de artistas y público en aras de la cualificación del campo artístico. Al considerarse profesionales, todo su esfuerzo se empezó a concentrar en lograr un espacio permanente que les permitiera seguir experimentando e indagando sobre el ámbito de su interés. Esta capacidad autorreflexiva es fundamental, pues va mostrando la intención de seguir ciertos objetivos ya planteados por los propios artistas y no por otras personas en su visión de lo culturalmente aceptable. Defendieron entonces sus decisiones alrededor de la creación artística y la evaluación estética sobre esta, algo fundamental en la constitución del campo de producción restringida, desde el cual se establece la autonomía relativa del arte. En Colombia se estaban definiendo las fronteras del campo teatral.

Esta actitud hizo que se resquebrajaran las relaciones con el Club de Amigos y, en especial, con los miembros directamente encargados de la parte financiera del grupo. Entre los pertenecientes a la parte artística también hubo desavenencias. Para este periodo, quienes aparecían como director y subdirector eran Cabrera y Reyes, pues varios de los miembros fundadores habían ido dejando el colectivo en situaciones conflictivas, como, por ejemplo, la expulsión de Mónica Silva ("Drama tras bambalinas", 21 de septiembre de 1959) o la contratación del francés Gilles Chancrin (El Espectador, 9 de agosto de 1959) para reformar el grupo, lo que llevó a la salida de Meneguetti (Meneguetti, 1959) y otros hacia la realización de teatro infantil (Arcila, 1983, pp. 63-64). Finalmente, terminaron por dividirse: El Búho-Odeón y el Teatro Experimental Independiente. Se abrió entonces una nueva etapa del teatro en este contexto, pues de allí surgieron los directores más importantes de las siguientes décadas (Moure, 1989, p. 49). El colectivo se hizo insostenible como proyecto independiente financiado por un público patrocinador, así que sus miembros se integraron a la Universidad Nacional, donde al poco tiempo, pasó a llamarse Teatro Estudio.

\section{LA CASA DE LA CULTURA}

Desde la década del sesenta, el teatro universitario se fue consolidando. En las universidades se dio un ambiente propicio para el desarrollo de diversas manifestaciones artísticas percibidas críticamente por un creciente público, en este caso ya no promovidas directamente 
por las directivas académicas sino provenientes del sector estudiantil (Florián Navas y Pecha Quimbay, 2013, p. 58). A pesar del entusiasmo permanente, la radicalización política que se vivía en el país y en general en el mundo, especialmente por el incremento de la insurgencia armada en el ambiente de la Guerra Fría y la creciente asociación que se hizo del estudiantado con aquella, influyeron en la mutua desconfianza entre artistas y representantes de diversas instituciones encargadas del sector educativo y cultural. A esto se suma la influencia creciente del proceso revolucionario cubano, el cual se hizo sentir fuertemente entre las décadas de 1960 y 1970, al trazar la ruta del "latinoamericanismo antiimperialista" (Espeche, 2010). En estas décadas también tiene lugar el boom latinoamericano, momento del feliz encuentro entre cultura y política, en particular por el apoyo a la transformación del tercer mundo a través de una cultura popular y revolucionaria (Gilman, 2003, pp. 13-14).

En este contexto se dio la expulsión de varios artistas de los centros académicos. El caso más sonado que cobró importancia, aunque no fue el único ${ }^{5}$, se dio con el montaje de Galileo Galilei de Bertolt Brecht bajo la dirección de Santiago García con el Teatro Estudio de la Universidad Nacional. El director decidió hacer eco de las relaciones establecidas por el autor dentro de su obra, en términos de la responsabilidad social del científico, y el uso de la bomba atómica al final de la Segunda Guerra Mundial, eco propagado por los estudiantes en el programa de mano repartido en el Teatro Colón durante el estreno. Aunque el montaje contó con un par de presentaciones, esta visión crítica no cayó muy bien a las directivas universitarias, que se encontraban tramitando un préstamo ante el Banco Interamericano de Desarrollo en el marco de la política Alianza para el Progreso, lo que inevitablemente llevó a la ruptura entre estas, los estudiantes y varios artistas.

Por esta razón, entre otras, se hizo manifiesta la necesidad de obtener espacios autónomos para la experimentación artística sostenida en un trabajo permanente, sin intervenciones de ningún tipo, es decir, independiente, lo cual obligaba a separarse de cualquier institución que no tuviera esta misma intención entre sus propósitos. Esta necesidad se sumó a otra expresada desde tiempo atrás, en colectivos como El Búho, de abrir un lugar donde se dinamizara el arte nacional a través de la integración de múltiples esfuerzos hechos desde diversas áreas. En 1963, Santiago García ya había expresado el plan de crear un centro cultural en Bogotá, para obtener una sede propia. Se proyectó un pequeño teatro de cámara de 250 sillas aproximadamente, en el que funcionaría un grupo de planta dirigido por él y por Dina Moscovici, una orquesta de cámara y un cineclub. Para ese año se alcanzó a anunciar tanto el apoyo de varios industriales como la gestión de recursos por parte del distrito, consistente en la donación de un lote donde se construiría la sede. La primera actividad del siguiente año sería hacer una subasta de cuadros de pintores famosos para obtener los fondos iniciales (“Verdadero acontecimiento será el debut de mañana del Teatro Estudio de Bogotá", 15 de diciembre de 1963).

Así, la expulsión de García en 1965 solo fue el detonante para llevar a cabo la iniciativa declarada desde tiempo atrás sobre la urgencia de consolidar un espacio de encuentro entre artistas e intelectuales. Con la salida de la Universidad Nacional, varias de las personas que trabajaban allí (Carlos José Reyes, Eddy Armando, Miguel Torres, entre muchos otros) decidieron crear la Casa de la Cultura de Bogotá ("La Candelaria: teatro cotidiano y participación popular", 1981). Ya no se trataba solo de conseguir un lugar de intercambio, sino de garantizar la independencia en la creación artística. Tras reuniones previas, la primera sede obtenida fue una pequeña sala de la Biblioteca Nacional, pero pronto se trasladaron a un espacio más 
adecuado en la Carrera 13 No. 20-64, acondicionado y puesto en funcionamiento gracias a donaciones hechas por varios amigos (aproximadamente 200) que se sumaron a los promotores (Suárez, 1974). A pesar de esta primera ayuda económica, desde el comienzo del proyecto se hizo evidente la urgencia de atraer recursos provenientes de otras fuentes como la empresa privada, instituciones educativas y obreras y, en especial, de un público asistente a las actividades programadas.

La Casa de la Cultura no se dedicaba solo al teatro, aunque, similar a El Búho, alrededor de esta actividad giró la posibilidad de consolidar otras de tipo artístico y cultural, porque, en principio, se consideró que a través del teatro se convocaba a las demás artes gracias al trabajo escenográfico y musical, por ejemplo. También existía la esperanza sobre el buen número de asistentes a las puestas en escena, con lo cual se podría subvencionar las otras labores con un público caracterizado por "distintos niveles intelectuales y afinidades electivas" ("Casa de la Cultura", 1966) apoyando el desarrollo de un arte nacional basado en las "corrientes modernas de pensamiento" ("Santiago García funda la Casa de la Cultura", 28 de marzo de 1966). La preocupación por el público seguía décadas después, cuantitativa y cualitativamente hablando, de la mano con la propia cualificación de los artistas, empezando por Bogotá, pero con el ánimo de extenderse al resto del país.

Se pensó entonces en albergar todas las artes posibles (Soldados, 1966): un espacio para cine no solo como un cineclub de difusión sino de promoción para la creación de cortos experimentales en 8 y 16 mm y seguir así a la producción de largometrajes. Algo similar sucedía con artes plásticas, pues no se pensó solo en una galería de exposiciones, sino en un lugar donde confluyeran diversas tendencias y técnicas en pintura, escultura, fotografía, caricatura, etc., actividades acompañadas de una labor didáctica apoyada en charlas, conferencias y debates en conjunto con las facultades de humanidades de algunas universidades. En música, con el patrocinio de Civio -Centro Internacional de Violín-y la Fundación Filarmónica Colombiana, se planeó realizar uno o dos conciertos de cámara al mes junto con recitales de diferentes géneros, empezando por jazz. Las representaciones teatrales irían de jueves a domingo, tratando de cubrir el repertorio mundial clásico y contemporáneo y de promover la dramaturgia nacional. Se planeó, además, crear una revista de difusión y discusión y una biblioteca especializada en temas de arte, para lo cual se había logrado una donación por parte de la Embajada de Francia y se esperaba otra similar por parte de la Embajada de Estados Unidos. Otra de las tareas a cumplir era el establecimiento de relaciones que permitieran el intercambio entre diversos grupos, en principio, latinoamericanos.

De nuevo, el teatro ocupó el papel central, pues, en parte, las principales directivas de la Casa se dedicaban a esta labor. Asimismo, se contaba con la importante movilización de personas y grupos gracias a los festivales de teatro y otras actividades, que generaban la necesidad de una sala para una ciudad que superaba el millón y medio de habitantes. Un espacio permanente era fundamental para el desarrollo de laboratorios artísticos, en especial cuando se quería realizar un trabajo de tipo colectivo cuyo resultado permaneciera más tiempo en cartelera, ya que, en varias ocasiones, montajes que tardaban un semestre en prepararse terminaban presentándose en no más de cuatro ocasiones. En general, se planteó como un proceso de doble vía: así como se incrementaba el público crítico, se movilizaba y cualificaba la creación artística.

El grupo organizador designó, para la junta directiva, a Santiago García como presidente; a Carlos José Reyes, Fernando Laverde, Mario Posada, Nirma Zárate y Miguel Sánchez como vo- 
cales; a Frank Preuss, Jacques Mosseri y Eduardo Gómez como suplentes, y a María Arango como revisora fiscal. La sede que consiguieron contaba con tres plantas, donde se acondicionó una sala de teatro con 150 sillas aproximadamente para las funciones de jueves a domingo, conferencias, recitales, conciertos, etc., junto a una sala de exposiciones. En el segundo piso se encontraba la cafetería y en el tercero las oficinas y los talleres de cine y fotografía (Voz Proletaria. 12 de mayo de 1966).

Soldados, dirigida por Carlos José Reyes, quien también se encargó de la adaptación de algunos textos de la novela La casa grande de Álvaro Cepeda Samudio, fue la obra con la que se inauguró la Casa el 30 de junio de 1966. De acuerdo con la programación, para el lunes de esa semana a las 7:00 p.m. estaba programada, en el marco de ciclo de conferencias, con El museo de oro de Leningrado de Jorge Zalamea, y a las 9:30 p.m. la previa de Soldados, obra que también iría el martes y miércoles, pero a la cual solo podían asistir estudiantes y obreros por un valor de \$3 la entrada (el valor normal era de \$10). El miércoles, el programa de música de cámara lo iniciaba la Fundación Filarmónica, con obras de Alejandro Scarlatti, Francesco Manfredini, Mozart, Bela Bartok, entre otros. El jueves 30 sería la inauguración oficial, con una exposición de dibujos de Pedro Alcántara Herrán y Soldados (Voz Proletaria, 23 de junio de 1966), obra de particular relevancia, pues con ella se manifestó claramente la intención de creación de obras nacionales, en este caso sobre la masacre de las bananeras, suceso de aparición recurrente en la dramaturgia del momento.

Durante su funcionamiento, las noticias sobre teatro eran las más frecuentes. Entre los estrenos estuvieron obras como La manzana de Jack Gelber y Persecución y asesinato de Jean Paul Marat, representado por el grupo teatral de los reclusos del Asilo de Charenton y dirigido por el Marqués de Sade de Peter Weiss. Con la primera, ganaron el premio a mejor grupo y una mención especial para el director Santiago García en el I Festival de Teatro de Cámara en 1966 -organizado por la Galería Colseguros y el Centro Universitario de Cultura. En montajes como este se seguía con la práctica de creación conjunta entre los artistas vinculados de alguna manera a la Casa, pues Enrique Grau fue el encargado de la escenografía.

Sin embargo, a un año de su apertura, aparecían de nuevo los problemas usuales. En una carta abierta a "socios y amigos" manifestaban que, a pesar de contar con la ayuda desinteresada de varios artistas, económicamente el proyecto no podía sostenerse, en parte, por los bajos costos de las entradas. Por eso solicitaban la ayuda de socios, amigos y simpatizantes, para que no lo dejaran morir, pues se trataba de una de las posibilidades de desarrollo artístico en el país (Voz proletaria, 5 de octubre de 1967). Junto a esta seria dificultad se sumaba otra igualmente preocupante: de nuevo, la escasez de público. Era usual que durante las tres primeras estuviera lleno, pero durante las siguientes semanas solo una sala vacía (Hurtado, 1966), cuando una de las principales tareas era mantener las obras en cartel por lo menos tres meses. Seguían funcionado las secciones planteadas desde el inicio, con una persona distinta encargada en cada una de ellas, pero las conferencias y mesas redondas no tuvieron gran acogida con los temas exclusivamente artísticos, así que tuvieron que ampliarlos; por ejemplo, hubo una charla sobre la píldora anticonceptiva. En el cineclub, si bien se habían logrado algunos ciclos, no había sucedido lo mismo con la consolidación de un grupo que se encargara de hacer cine nacional, y en música, la Filarmónica de Colombia se hallaba en receso por escasez de recursos, no había funcionado el disco club ni el cuarteto que se había intentado formar y solo en parte lo hacía el jazz-club. Más o menos se habían podido sostener las exposiciones y en teatro hasta ahora se estaba conformando un grupo de planta cuyos mayores obstáculos 
también eran los problemas económicos y el precario desenvolvimiento del compromiso de los actores frente a su papel cultural (Voz proletaria. 06 de julio de 1967).

A pesar de estas constantes decepciones, se lograron resultados interesantes, especialmente en el teatro. Una de ellas fue el intercambio iniciado allí con el Teatro Experimental de Cali. El Tec -primero Teatro Escuela de Cali- se había fundado en 1955 y pronto fue considerado como la primera compañía profesional y oficial del país (Piedrahíta, 1996, p. 41), la cual dejará de serlo cuando le sean retirados los auxilios oficiales que los sostenían'; en ese momento fue cuando cambió su nombre. Tempranamente, fue uno de los grupos que al tiempo que se ponía al día con la vanguardia mundial también intentó contribuir, a través del teatro experimental, al desarrollo de un arte nacional (Rizk, 1990, p. 8), lo que le valió en parte que durante los cuatro primeros festivales de teatro, de 1958 a 1961, ganara casi todos los premios. De este intercambio partirá el esfuerzo por crear la Corporación Colombiana de Teatro, conformada junto con otros grupos con el ánimo de defender la independencia de los artistas frente a presiones de distinto tipo, especialmente la ejercida por medio de la censura.

Pero tres años después los problemas económicos ya no dieron espera. Por no poder pagar los arrendamientos, tuvieron que abandonar la casa, razón por la cual se vieron obligados a buscar los recursos para adquirir un lugar propio que, gracias en gran medida a un auxilio del Concejo Distrital por \$300.000 gestionado inicialmente por Álvaro Gómez Hurtado a través del concejal Gabriel Melo Guevara, se consiguió en el barrio La Candelaria, sector en el cual se planeaba impulsar el desarrollo cultural de la ciudad. Quedaron en parte hipotecados, pero con donaciones de nuevo de amigos con recursos interesados en este proyecto lograron adaptar el espacio (Suárez, 1974).

Entre 1966 y 19727, otros montajes recordados fueron El matrimonio de Witold Gombrowicz, La patente de Luigi Pirandello, La gaviota de Anton Chejov, Metamorfosis de Carlos José Reyes -basada en el texto de Kafka- Historia del zoológico de Edward Albee, La cocina de Arnold Wesker, Fando y Lis de Fernando Arrabal, montajes donde seguían colaborando artistas plásticos como Enrique Grau, Juan Manuel Lugo, Feliza Bursztyn, David Manzur y Ana Mercedes Hoyos ("Teatro La Candelaria 1966-1996", 1997, pp. 12-38). En este terreno hicieron, además, parte de lo que querían, es decir, transitar por autores clásicos y contemporáneos de Esquilo a Brecht, pasando por Pirandello y Shakespeare, así como por algunos colombianos en la puesta en escena de obras de Carlos José Reyes y Enrique Buenaventura. Asistieron a varios festivales internacionales, como en 1971 al de Nancy junto con el Tec y la Mama, siendo uno de los países con mayor delegación entre América Latina, grupos orientados ya hacia el sector estudiantil y obrero, y a festivales nacionales con intercambios en especial entre Bogotá y Cali (El Tiempo, 1 de abril de 1971), así como eventos en semanas culturales en barrios del sur de la ciudad (Voz proletaria, 24 de septiembre de 1970). Otros ámbitos en los que se desplegaron se muestran en actividades como cursos de teatro, programación del cineclub, conferencias, exposiciones de pintura y fotografía, y los Festivales Internacionales de la Canción Protesta. Al poco tiempo de estar en esta sede, pasó de ser la Casa de la Cultura al actual Teatro La Candelaria; el nombre les resultaba muy institucional en un momento en que, por iniciativa gubernamental, se empezaron a crear varias casas de la cultura en Bogotá.

Pero en este periodo lo más destacable son las recurrentes discusiones sobre la función social del arte, en especial su relación con un público popular. En 1967, gracias a la promoción del II Festival de Teatro de Cámara por parte de la Casa de la Cultura, desde el Frente Común del Arte y la Literatura, Fausto Cabrera y Enrique Molina lanzaron una fuerte crítica a lo que consideraban 
la defensa de posiciones seudorebeldes y seudo progresistas ("Boletín No. 1 Frente Común en el Arte y la Literatura", 1967). Calificaban el trabajo de la Casa de extranjerizante y reaccionario ya que el teatro de cámara estaba dirigido a minorías intelectuales mientras las clases oprimidas requerían de un teatro didáctico y directo ("Carta abierta dirigida por la Escuela de Artes Escénicas de Medellín a la Casa de la Cultura de Bogotá", 1967). Carlos José Reyes pronto dio respuesta a estas acusaciones insistiendo en las diferencias entre un teatro de propaganda enfocado en mostrar las luchas de clases como un asunto moral entre buenos y malos frente a otro que favoreciera la construcción de una perspectiva crítica en el espectador.

La pregunta que hacía Reyes resultaba bastante pertinente al no separar arte y sociedad: ¿cómo producir un arte para las masas populares cuando estas eran prácticamente inexistentes en un país con un precario desarrollo industrial, es decir, con un escaso proletariado urbano? (Reyes, 1968). Era imposible entonces construir teatros obreros y su exaltación solo podía corresponder a un "revolucionarismo anacrónico". No obstante, esta polémica en torno al apoyo a las clases populares en su lucha revolucionaria por la emancipación a lo largo de toda América Latina ocupó el centro de los debates de los próximos años, en especial en el naciente Movimiento Nuevo Teatro, periodo que excede el abordado en este documento. Basta con mencionar otras actividades de la Casa de la Cultura en esta dirección como la creación del Centro de la Canción Protesta en 1967, que al poco tiempo consolidó las Peñas Culturales, y en 1970 el I Festival de la Canción Protesta y el I Encuentro Nacional de Artistas y Obreros del cual surgieron los Sábados Obreros ("Teatro La Candelaria 1966-1986", 1986, pp. 4-5). Sin embargo, Santiago García considera que para ese entonces el grupo no tenía una línea política o ideológica definida (Duque Mesa y Prada Prada, 2004, p. 218).

\section{CONSIDERACIONES FINALES}

Los intentos por consolidar espacios conjuntos de creación, experimentación e investigación en el arte y otras esferas culturales son fundamentales para su desenvolvimiento, pues tienen que ver con la experiencia inmediata de los seres humanos, su contacto directo con distintos ámbitos de conocimiento y con la posibilidad de desarrollo de este conocimiento en términos generacionales. Esta intención no viene de la nada, sino de la realidad que se hace evidente a través de la existencia de diversos esfuerzos aislados que por encontrarse en esta condición tienden a ser mucho más débiles y obviamente desarticulados. Sociológicamente, esto es explicado por Elias cuando establece la conexión histórica entre adquisición de conocimiento y posibilidad de control en términos de redireccionar las acciones humanas para alcanzar ciertos propósitos (Elias, 1990, pp. 66-68).

Las dos experiencias aquí presentadas tienen que ver con los planes de artistas e intelectuales frente a objetivos sociales de más largo aliento: desarrollo de un arte original que diera cuenta tanto de los procesos por los que ha atravesado una sociedad particular así como de las transformaciones de los seres humanos que se encuentran en ella. Esta particularidad se leyó simultáneamente con la comprensión sobre la oportunidad de aportar en algo al desenvolvimiento cultural no solo de estos artistas e intelectuales sino de la población en general, la cual durante bastante tiempo estuvo marginada por varias razones, ya fuera por desinterés o por la imposibilidad de acceso a los bienes culturales. Fue claro que estos procesos iban de la mano, pues no tenía sentido crear para unos cuantos especialistas cuando se habían planteado una función social del arte mucho más amplia, la cual estaba expresada en el tránsito de 
la orientación hacia los intelectuales y los estudiantes (El Búho) a los obreros y demás clases populares (última etapa de la Casa de la Cultura).

Dichos esfuerzos encontraron apoyo y soportes efímeros. Los más problemáticos de conseguir y sostener tenían que ver con dos aspectos centrales: la capacidad de recabar recursos de los agentes y grupos que los poseían, fueran privados o públicos, y la necesidad de formar un público que no solo contribuyera económicamente sino, y esto era tal vez lo más importante, críticamente con su propia percepción sobre el arte que se necesitaba y se deseaba construir. Las dos experiencias presentadas, sin embargo, no resultaron tan exitosas en sus propósitos iniciales en el corto plazo, aunque la Casa de la Cultura se transformó en el Teatro La Candelaria, uno de los más importantes del país y la región desde el momento de su fundación, y aún hoy existente. Como colectivos, no lograron un desarrollo satisfactorio en todas las esferas artísticas y educativas que se habían planteado, pues en el camino se fueron estrellando tanto con las dificultades ya mencionadas como con la creciente especialización que hizo desvanecer proyectos de esta magnitud. Aun así, dieron el impulso inicial para la transformación del arte durante la segunda mitad del siglo XX, con figuras que aún hoy son recordadas y cuyos nombres han aparecido a lo largo de este documento.

Para el ámbito específico del teatro, el panorama fue otro. De colectivos como estos surgieron buena parte de los directores y los grupos que llevaron esta actividad a ocupar un lugar destacado en el ámbito nacional, regional y, en muchas ocasiones, internacional. La multiplicación de grupos, festivales, escuelas y centros de formación de distinto tipo, la configuración de una dramaturgia nacional así como la relación entre teatristas y diversos sectores de la población conformando organizaciones como la Corporación Colombiana de Teatro, la Asociación Nacional de Teatro Universitario o estableciendo convenios con las centrales obreras, hicieron del teatro colombiano una de las referencias obligatorias en cuanto desarrollo artístico y la vinculación de este con la transformación cultural desde la configuración de un público crítico.

Este último aspecto plantea, sin embargo, mayores problemas para llegar a una conclusión; primero, porque es un proyecto inacabado, pero, principalmente, porque tendrían que relacionarse otros fenómenos propios del periodo histórico analizado y sus consecuencias actuales. Por lo menos en el momento en que existieron colectivos como El Búho y la Casa de la Cultura, siempre surgió la pregunta por el público, y aunque este se logró ampliar posteriormente hacia el estudiantil, obrero y otros sectores populares, la práctica artística todavía se encuentra bastante alejada de la cotidianidad de la mayoría de las personas y recae más, por la misma especialización de su lenguaje, en aquellas que por distintas rutas han adquirido las herramientas de comprensión, análisis y crítica.

\section{NOTAS}

1 Como la compañía de Doña María Guerrero y Don Fernando Díaz de Mendoza, la de Margarita Xirgú, el concertista polaco Ignaz Friedmann o el director Louis Jouvet (Romero Lozano, 1948a).

2 Uno de los medios impresos con mayor cubrimiento fue El Siglo con Enrique de la Hoz, también director teatral, como crítico permanente. Algunos de sus comentarios seguro eran comprendidos por las personas vinculadas al teatro entre creadores y espectadores, tal vez no así para los legos. Por ejemplo, sobre el montaje de Antígona a cargo del grupo de la Televisora Nacional presentada en 1957 planteaba: "Comenzar a moverse las figuras, a moverse precisamente en ausencia de 'movimiento' y desvanecerse la belleza inicial 
-y para no reaparecer- todo fue uno. Entonces, a falta de "fatum", de relieve en el diálogo, la escenografía se quedaba más desnuda, menos bien vestida de lo que una mínima exigencia estaba reclamando. (...) No es justificable un graderío de escalones descomunales de imposible tránsito, forrado de tela azul, pero asomando los muñones de la carpintería. Ni los elementos de mobiliario rojo. O vi mal en una "Antígona" europea del año 1954, o la armonía del color estaba en blanco y negro, preconizado por Anouilh y ordenada desde el frack de Creón. Y desde las canas de su pelo, aquí apenas las de la madurez incipiente. ¿Detalles? De detalles se componen las obras de arte" (El Siglo, 26 de octubre de 1957). Información amplia sobre este proceso en Aldana Cedeño y Meneses Duarte (2012).

3 Los nombres que aparecen son Jorge Gaitán Durán, Pedro Gómez Valderrama, Guillermo Cano, entre otros quienes se encargaban básicamente de la ayuda económica. Para 1959 el grupo contaba con más de 180 patrocinadores.

4 Una de sus principales difusoras fue Dina Moscovici, brasilera formada en París bajo la escuela de Charles Dullin, quien llegó al país en 1956 -al casarse con Jorge Gaitán Duran-, ejerciendo inicialmente como docente en la Escuela Nacional de Arte Dramático (Moscovici, 2012). Por esa misma época la producción artística y teórica de Brecht ya había tenido cierta difusión. Es de notar tanto el primer montaje de una obra suya, La condena de Lúculo por el grupo de Teatro Experimental de la Universidad Nacional en 1957 bajo la dirección de Enrique Pontón, quien ganó el segundo premio a mejor director en el I Festival de Teatro (E) Siglo, 2 de noviembre de 1957), como uno de los artículos de mayor discusión en el momento, De Stanislavski a Brecht de Enrique Buenaventura (1958b), pues ponía sobre la arena el tomar partido por el teatro brechtiano frente a la inclinación dominante en los grupos colombianos de vanguardia seguidores de Stanislavski, si se quería contribuir a la formación de una percepción crítica sobre los conflictos humanos. Además, Santiago García había realizado un stage en el Berliner Ensemble durante su estancia en algunas escuelas europeas entre 1959 y 1960

5 Al Tec le fue retirado el apoyo con presupuesto público en 1967 por el montaje de La trampa, escrita por Buenaventura y dirigida por Santiago García. En 1969 se destituye a Buenaventura de la Escuela Departamental de Cali junto a otros profesores adscritos a la Facultad de Bellas Artes. Algo similar sucedió con el grupo de la Universidad de los Andes, dirigido por Ricardo Camacho, cuando fueron retenidos por el F-2 en el aeropuerto de Medellín, ciudad donde presentarían Discurso sobre Vietnam de Peter Weiss.

6 Esto fue cuando Santiago García dirigió al Tec en el montaje de La trampa. La trama se basa en la vida de Ubico, dictador centroamericano que tuvo grandes problemas, especialmente con alzamientos campesinos. Por algunas escenas el gobierno tomó la obra como una burla a las fuerzas armadas así que fue prohibida por la Gobernación del Valle (García, 1968).

7 Año en que cambia su nombre por Teatro La Candelaria y estrenan la primera creación colectiva, Nosotros los comunes.

\section{REFERENCIAS}

Aldana Cedeño, Janneth y Meneses Duarte, Cristian. Los colectivos experimentales en la emergencia del teatro moderno en Colombia. Colección Pensar el Teatro. Bogotá: Ministerio de Cultura, 2012.

Altamirano, Carlos. Términos críticos de la sociología de la cultura. Buenos Aires: Paidós, 2002.

Andrade González, Gerardo. "Osorio y el teatro en Colombia". El Tiempo, Bogotá, 28 de agosto de 1966.

Arcila, Gonzalo. Nuevo teatro en Colombia. Actividad creadora y política cultural. Bogotá: Ceis, 1983.

Argaez, Camila y Franco, Maria. “Bernardo Romero Lozano, pionero y maestro de la televisión colombiana". Tesis de pregrado, Universidad de la Sabana. Bogotá: Facultad de Comunicación, 1986.

"Atmósfera teatral en el Colón". El Espectador, Bogotá, 23 de agosto de 1958.

Becker, Howard. Art worlds. London: University of California Press, 1982. 
"Boletines de la Radiodifusora Nacional", núm. 172, noviembre de 1958. Archivo Fonoteca Nacional.

“Boletín No. 1 del Frente Común en el Arte y la Literatura". Medellín, mayo de 1967. Archivo Casa del Teatro Gilberto Martínez.

Bourdieu, Pierre. "El mercado de los bienes simbólicos". En Creencia artística y bienes simbólicos. Buenos Aires: Aurelia Rivera, 2003. 85-154.

Bourdieu, Pierre. Las reglas del arte. Génesis y estructura del campo literario. Barcelona: Anagrama, 1995.

Buenaventura, Enrique. "Consideraciones sobre los problemas del desarrollo del teatro en los departamentos". Cuadernillo del Il Festival de Teatro de Bogotá. Bogotá: Teatro Colón, 1958a.

Buenaventura, Enrique. "De Stanislavski a Brecht." Revista Mito, vol. IV, núm. 21 septiembreoctubre. 1958b). Bogotá. 177-182.

Cabrera, Fausto. "Comentarios sobre el teatro en Colombia". Cuadernillo del II Festival de Teatro de Bogotá. Bogotá: Teatro Colón, 1958a.

Cabrera, Fausto. "La escuela de vivencia". El Espectador, Bogotá, 26 de octubre y 16 de noviembre de 1958b.

“La verdad sobre el teatro El Búho". Magazín Dominical El Espectador, Bogotá. 1 de abril de 1979.

"Carta abierta dirigida por la Escuela de Artes Escénicas de Medellín a la Casa de la Cultura de Bogotá". Medellín, mayo de 1967. Archivo Casa del Teatro Gilberto Martínez.

Casa de la Cultura 1966. Programa de Inauguración. Biblioteca Gilberto Martínez, Archivo Casa del Teatro. Medellín. 29.

"Casa de la Cultura". Voz proletaria, Bogotá, 12 de mayo de 1966.

Corredor, Consuelo. Los límites de la modernización. Bogotá: Cinep, 1992.

“Drama tras bambalinas". El Espectador, Bogotá, 21 de septiembre de 1959.

De la Hoz, Enrique. El Siglo, Bogotá, 26 de octubre de 1957.

“Dos tendencias del teatro nacional". Revista de las Indias, vol. 57 (1943). Bogotá. 333-334

Duque Mesa, Fernando y Prada Prada, Jorge. Santiago García. El teatro como coraje. Bogotá: Ministerio de Cultura, 2004.

"Ecos del II festival: comentarios al fallo del jurado". El Siglo, Bogotá, 23 de septiembre de 1958.

El Espectador, Bogotá, 19 de septiembre de 1955.

El Espectador, Bogotá, 16 de agosto de 1958.

El Espectador, Bogotá, 23 de agosto de 1958

El Espectador, Bogotá, 9 de agosto de 1959.

El Espectador, Bogotá, 29 de julio de 1960.

El Espectador, Bogotá, 11 de septiembre de 1960.

El Tiempo, Bogotá, 1 de abril de 1971.

El Siglo, Bogotá, 2 de noviembre de 1957.

El Siglo, Bogotá, 29 de junio de 1960.

El Siglo, Bogotá, 27 de abril de 1960.

Elias, Norbert. "Hacia una teoría de los procesos sociales". En La civilización de los padres y otros ensayos. Bogotá: Norma, 1998. 447-532.

Elias, Norbert. Compromiso y distanciamiento. Barcelona: Península, 1990.

Espeche, Ximena. "De una isla a otra: intelectuales uruguayos y América Latina como problema a mediados del siglo XX". Revista Anclajes, núm. 14 (2010) Santa Rosa: Argentina. 51-72. 
Florián Navas, Carmen Alicia y Pecha Quimbay, Patricia. El teatro la Candelaria y el movimiento teatro en Bogotá 1950-1991. Bogotá: Secretaría General Alcaldía Mayor de Bogotá, 2013.

Font Castro, José. "Teatro experimental en Bogotá". El Tiempo, Bogotá, sec. Lecturas dominicales, 27 de febrero de 1955.

García, Santiago. "Estamos haciendo un teatro muy comprometido". Conjunto, núm. 7 (1968). Santa Rosa: Argentina: 51-72.

Gilman, Claudia. De la pluma al fusil. Debates y dilemas del escritor revolucionario en América latina. Buenos aires: Siglo XXI, 2003.

Gómez Valderrama, Pedro. "El revés de la máscara". Cuadernillo del I/ Festival de Teatro de Bogotá. Bogotá: Teatro Colón, 1958.

Henderson, James. La modernización en Colombia. Los años de Laureano Gómez 1889-1965. Medellín: Universidad de Antioquia, 2006.

Hurtado, Amparo. “Vuelve una pieza atrevida: 'La manzana' Teatro de vanguardia y absurdo en Bogotá". El Vespertino, Bogotá, 7 de septiembre de 1966.

“La Candelaria: teatro cotidiano y participación popular". Guión, núm. 224 (1981). 222.

Meneguetti, Aristides. “El Búho ha muerto". El Espectador, Bogotá, 7 de septiembre de 1959.

Moscovici, Dina. El Tiempo, Bogotá, 10 de noviembre de 1957.

Moscovici, Dina. Entrevista personal octubre-noviembre de 2012.

Moure, Consuelo. El teatro universitario colombiano. Bogotá: Becas Colcultura, 1989.

Norden, Francisco. "La violencia de la cultura". Mito, vol. 17 (1957-58). 349-350

Osorio, Luis Enrique. "Los éxitos del nacionalismo teatral." El Tiempo, Bogotá, 26 de marzo de 1961

Pecaut, Daniel. Orden y violencia 1930-1963. Bogotá: Cerec-Siglo XX, 1985.

Piedrahíta, Guillermo. La producción teatral en el movimiento del Nuevo Teatro. Cali: Taller gráficoCCT, 1996.

Pontón, Enrique. "El teatro experimental y la universidad". Cuadernillo del I/ Festival de Teatro de Bogotá. Bogotá: Teatro Colón, 1958a.

Reyes, Carlos José. "Seis personajes en busca de Eliot". Magazin Dominical Espectador, Bogotá, 10 de abril de 1960.

Reyes, Carlos José. "Posibilidades y problemas del teatro popular en Colombia". Revista Casa de la Cultura, Bogotá, núm. 1 (1968). 19-25.

Rizk, Beatriz. "La dramaturgia de Enrique Buenaventura". Tesis doctoral, The City University of New York. New York: Facultad de Filosofía 1990.

Rizzo Otero, Harold. El Tiempo, Bogotá, 6 de septiembre de 1959.

Rizzo Otero, Harold. El Espectador, Bogotá, 18 de septiembre de 1960.

Rizzo Otero, Harold. El Espectador, Bogotá, 25 de septiembre de 1960.

Romero Lozano, Bernardo. "Historia del Teatro Colón". Lecturas Dominicales El Tiempo, Bogotá, 18 de julio de 1948a.

Romero Lozano, Bernardo. "Vida del teatro Colón". Lecturas Dominicales El Tiempo, Bogotá, 1 de agosto de 1948b.

"Santiago García funda la Casa de la Cultura". Cromos, Bogotá, 28 de marzo de 1966.

Sierra Mejía, Rubén. “Política y cultura durante la República Liberal." Aleph, vol. 43, núm. 151 Manizales (2009). 21-31.

Silva, Renán. República liberal, intelectuales y cultura popular. Medellín: La carreta histórica, 2005. 
Silva, Renán. Sociedades campesinas, transición social y cambio cultural en Colombia. Medellín: La carreta histórica, 2006.

Programa de mano Soldados. Medellín: Biblioteca Gilberto Martínez, Archivo Casa del Teatro, 1966.

Suárez, Gilma. "Un artista llamado Santiago García". Diario del Caribe, Barranquilla, 16 de junio de 1974.

“Teatro Colón. Escuela de Arte Dramático. Cuadernillo." Bogotá: Ministerio de Educación Nacional, 1951-1952.

“Teatro La Candelaria 1966-1986". Revista núm. 1. Teatro La Candelaria Bogotá, 1986.

“Teatro La Candelaria 1966-1996". Bogotá: Instituto Colombiano de Cultura, 1997.

Téllez, Hernando. Cincuenta años de la radiodifusión en Colombia. Bogotá: Bedout, 1974.

Vajta, Ferenc. "Las perspectivas del II Festival de Teatro." Cuadernillo II Festival de Teatro, 1958.

"Verdadero acontecimiento será el debut de mañana del Teatro Estudio de Bogotá". El Siglo, Bogotá, 15 de diciembre de 1963.

Vivas, Nelly. El Espectador, Bogotá, 23 de agosto de 1959.

Voz Proletaria, Bogotá, 12 de mayo de 1966.

Voz proletaria, Bogotá, 23 de junio de 1966.

Voz proletaria, Bogotá, 6 de julio de 1967.

Voz proletaria, Bogotá, 5 de octubre de 1967.

Voz proletaria, Bogotá, 24 de septiembre de 1970.

\section{Cómo citar este artículo:}

Aldana Cedeño, Janneth. "Colectivos artísticos en Bogotá. La transformación del quehacer artístico entre 1950 y 1970 promovida por El Búho y La Casa de la Cultura". Cuadernos de Música, Artes Visuales y Artes Escénicas, 9 (2), 193-214, 2014. http://dx.doi.org/10.11144/Javeriana.mavae9-2.cabt 
